\title{
The Effect of Smoking on the Outcome of Matrix- Based Autologous Chondrocyte Implantation: Data from the German Cartilage Registry
}

\author{
Volker M. Betz, MD ${ }^{1}$ Martin Holzgruber, MD ${ }^{1}$ Johanna Simon, MD ${ }^{1}$ Felix Uhlemann, MD ${ }^{1}$ \\ Philipp Niemeyer, MD²,3 Peter E. Müller, MD ${ }^{1}$ Thomas R. Niethammer, MD ${ }^{1}$
}

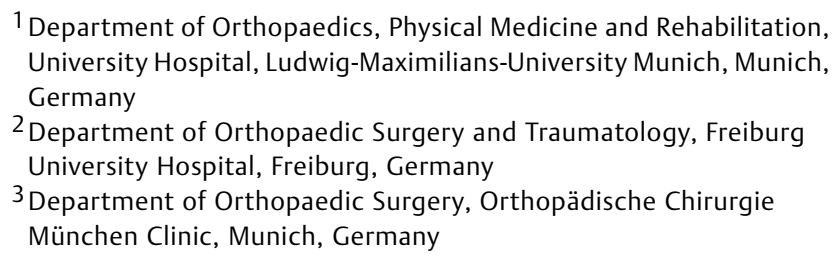

Address for correspondence Volker M. Betz, MD, Department of Orthopaedics, Physical Medicine and Rehabilitation, University Hospital, Ludwig-Maximilians-University Munich, Marchioninistr. 15, Munich 81377, Germany (e-mail: volker.betz@yahoo.com).

J Knee Surg 2023;36:181-187.

\begin{abstract}
Keywords

- smoking

- autologous cartilage implantation

- cartilage repair

- knee

- German Cartilage Registry

Smoking is known to have various deleterious effects on health. However, it is not clear whether smoking negatively affects the postoperative outcome following matrix-based autologous cartilage implantation (MACl) in the knee. The purpose of this study was to evaluate the effect of smoking on the outcome of $\mathrm{MACl}$ in the knee. A total of 281 patients receiving $\mathrm{MACl}$ in the knee between 2015 and 2018 were registered in the German Cartilage Database. The cohort was divided into ex-smokers, smokers, and nonsmokers. Data regarding the Knee Injury and Osteoarthritis Outcome Score (KOOS), the numeric rating scale (NRS) for pain, and satisfaction with the outcome were analyzed and compared. Follow-ups were performed at 6,12 , and 24 months after surgery. Of the 281 patients, 225 (80.1\%) were nonsmokers, 43 (15.3\%) were smokers, and $13(4.6 \%)$ were ex-smokers. The three groups were comparable with respect to age, sex, body mass index (BMI), height, defect size, the need for additional reconstruction of the subchondral bone defect, number of previous knee surgeries, and defect location. However, nonsmokers had a significantly lower weight as compared with smokers. Besides a significantly lower preoperative NRS of nonsmokers as compared with smokers, there were no significant differences between the three groups with respect to KOOS, NRS, and satisfaction at 6,12 , and 24 months of follow-ups. The present study of data retrieved from the German Cartilage Registry suggests that the smoking status does not influence the outcome of $\mathrm{MACl}$ in the knee.
\end{abstract}

Focal cartilage defects can severely impact the quality of patient's lives due to severe pain and impaired function. These patients are also at a higher risk to develop osteoarthritis which leads to further destruction of the joint and may lead to longterm disability. Even partial thickness focal defects under $1 \mathrm{~cm}$ increase the risk of further cartilage damage in persons who

received

October 15, 2020

accepted after revision

May 1, 2021

article published online

July 8,2021

have or are at high risk to develop osteoarthritis. ${ }^{1}$ Current treatment options of focal cartilage defects of the knee joint include microfracture, ${ }^{2}$ osteochondral autograft transfer, ${ }^{3}$ osteochondral allograft transplantation, ${ }^{4}$ and autologous chondrocyte implantation (ACI). ${ }^{5}$ The third-generation ACI method comprises of autologous cartilage cells seeded on a three-

(c) 2021. Thieme. All rights reserved. Thieme Medical Publishers, Inc., 333 Seventh Avenue, 18th Floor, New York, NY 10001, USA
DOI https://doi.org/ 10.1055/s-0041-1731456. ISSN 1538-8506. 
182 Smoking and Autologous Chondrocyte Implantation Betz et al.

dimensional collagen scaffold. This approach requires the harvest of cartilage from the patient, isolation, and expansion of chondrocytes in vitro over several weeks, seeding of the cells on the matrix, and subsequently the implantation of the cellscaffold construct into the patient's focal cartilage defect. ${ }^{6}$ Third-generation $\mathrm{ACI}$ is applied for full-thickness cartilage defects of a size of at least $2.5 \mathrm{~cm}^{2}$, while patients are typically up to approximately 55 years without certain concomitant pathologies, including advanced arthritis, rheumatoid arthritis, or subtotal resected meniscus in an impacted compartment. ${ }^{7}$

Since 2004, in many countries complete national smoking bans in public places were adopted due to the well-known deleterious effects of first-hand and second-hand smoke exposure. $^{8}$ It is estimated that smoking is responsible for approximately 6 million deaths worldwide per year. ${ }^{9}$ Despite this fact, the prevalence of smoking in Germany remains high with $28 \%{ }^{10}$ The estimated global prevalence of daily tobacco smoking among the adult population was $15.2 \%$ in $2015 .^{11}$

Several investigations have demonstrated that smoking has adverse effects on the musculoskeletal system. ${ }^{12}$ In particular, it was reported that smoking is associated with poorer outcomes following orthopaedic surgical procedures, while most of these reports are derived from studies on bone healing. ${ }^{13-17}$ Another research work demonstrated that smoking increases the risk of early meniscus repair failure. ${ }^{18}$ In this retrospective study, significantly more smokers than nonsmokers needed revision surgery after meniscus repair leading to the conclusion that smoking status should be added to the list of factors influencing the decision between meniscus repair and meniscectomy. ${ }^{18}$ The authors explained the poorer outcome with the detrimental effects of smoking on tissue perfusion causing vasoconstriction and platelet aggregation. Similarly, it was found that smoking has a negative effect on rotator cuff repair, leading to impaired healing and poorer clinical outcomes. ${ }^{19}$ The authors concluded that smoking cessation would benefit patients improving clinical outcome.

Interestingly, the relationship between smoking and osteoarthritis is controversial. ${ }^{12}$ Cartilage is an avascular tissue receiving oxygen and nutrients from the synovial fluid by diffusion. Therefore, cartilage may not be as negatively affected by smoking as other tissues.

Table 1 The patient cohort investigated in the present study was divided into three groups: ex-smokers, nonsmokers, and smokers

\begin{tabular}{|c|c|c|c|c|}
\hline Demographics & Ex-smokers & Smokers & Nonsmokers & $p$-Value \\
\hline Age $(y)$ & $40.5 \pm 11.2$ & $36.8 \pm 10.1$ & $34.6 \pm 10.5$ & 0.089 \\
\hline \multicolumn{4}{|l|}{ Sex } & \multirow[t]{3}{*}{0.309} \\
\hline Female & $30.8 \%$ & $34.9 \%$ & $45.1 \%$ & \\
\hline Male & $69.2 \%$ & $65.1 \%$ & $54.9 \%$ & \\
\hline Body mass index $\left(\mathrm{kg} / \mathrm{m}^{2}\right)$ & $27.5 \pm 4.2$ & $26.5 \pm 3.6$ & $25.4 \pm 3.8$ & 0.054 \\
\hline Weight (kg) & $85.2 \pm 15.4$ & $83.5 \pm 13.6$ & $79.1 \pm 13.5$ & 0.055 \\
\hline Height (cm) & $175.4 \pm 6.6$ & $176.4 \pm 9.5$ & $175.3 \pm 9.2$ & 0.755 \\
\hline Defect size $\left(\mathrm{mm}^{2}\right)$ & $429.9 \pm 170.2$ & $410.7 \pm 192.5$ & $426.7 \pm 201.3$ & 0.888 \\
\hline Repair of subchondral bone & $15.4 \%$ & $9.3 \%$ & $11.6 \%$ & 0.054 \\
\hline \multicolumn{4}{|l|}{ Number of previous knee surgeries } & \multirow[t]{7}{*}{0.599} \\
\hline 0 & $46.2 \%$ & $37.2 \%$ & $44.9 \%$ & \\
\hline 1 & $15.4 \%$ & $37.2 \%$ & $35.6 \%$ & \\
\hline 2 & $7.7 \%$ & $11.6 \%$ & $11.1 \%$ & \\
\hline 3 & $23.1 \%$ & $4.7 \%$ & $6.2 \%$ & \\
\hline 4 & $0 \%$ & $9.3 \%$ & $1.3 \%$ & \\
\hline 5 & $7.7 \%$ & $0 \%$ & $0.9 \%$ & \\
\hline \multicolumn{4}{|l|}{ Defect localization } & \multirow[t]{7}{*}{0.688} \\
\hline Patella & $30.8 \%$ & $32.6 \%$ & $39.1 \%$ & \\
\hline Trochlea & $7.7 \%$ & $7.0 \%$ & $12.9 \%$ & \\
\hline Medial femoral condyle & $38.5 \%$ & $44.2 \%$ & $35.1 \%$ & \\
\hline Lateral femoral condyle & $23.1 \%$ & $16.3 \%$ & $9.8 \%$ & \\
\hline Medial tibial plateau & $0 \%$ & $0 \%$ & $1.3 \%$ & \\
\hline Lateral tibial plateau & $0 \%$ & $0 \%$ & $1.8 \%$ & \\
\hline
\end{tabular}

Notes: Recorded parameters were age, sex, body mass index, weight, height, defect size, the need for additional reconstruction of the subchondral bone defect, number of previous knee surgeries, and defect location.

The weight of nonsmokers was significantly lower than that of smokers $(p=0.032)$.

There was no statistically significant difference between the three groups with respect to all other parameters. 


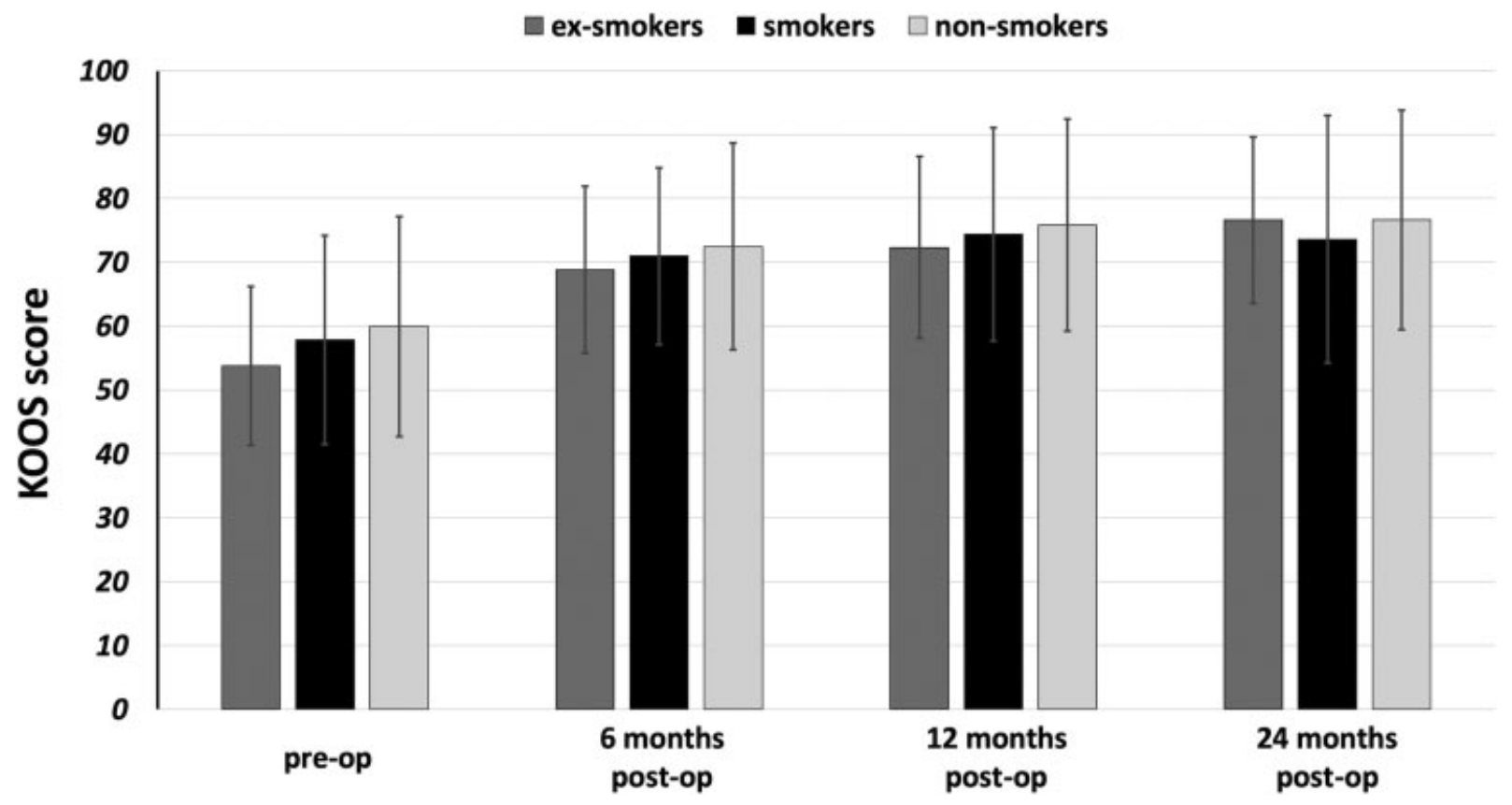

Fig. 1 Clinical outcomes of ex-smokers, non-smokers and smokers analyzed by means of the Knee Injury and Osteoarthritis Outcome Score (KOOS). There were no significant differences detected between the three groups at 6,12 , and 24 months follow-ups. Post-op, postoperative; Pre-op, preoperative.

The purpose of this study was to investigate whether smoking influences the outcome following treatment of focal cartilage defects in the knee by third-generation ACI. Due to the well-known general deleterious health effects of smoking, we hypothesized that smokers show worse outcomes after third-generation ACI.

\section{Methods}

\section{Patients and German Cartilage Registry}

Data were obtained from the German Cartilage Registry. ${ }^{20} \mathrm{~A}$ total of 281 patients assigned for third-generation ACI between 2015 and 2018 were included in this study. Surgeons
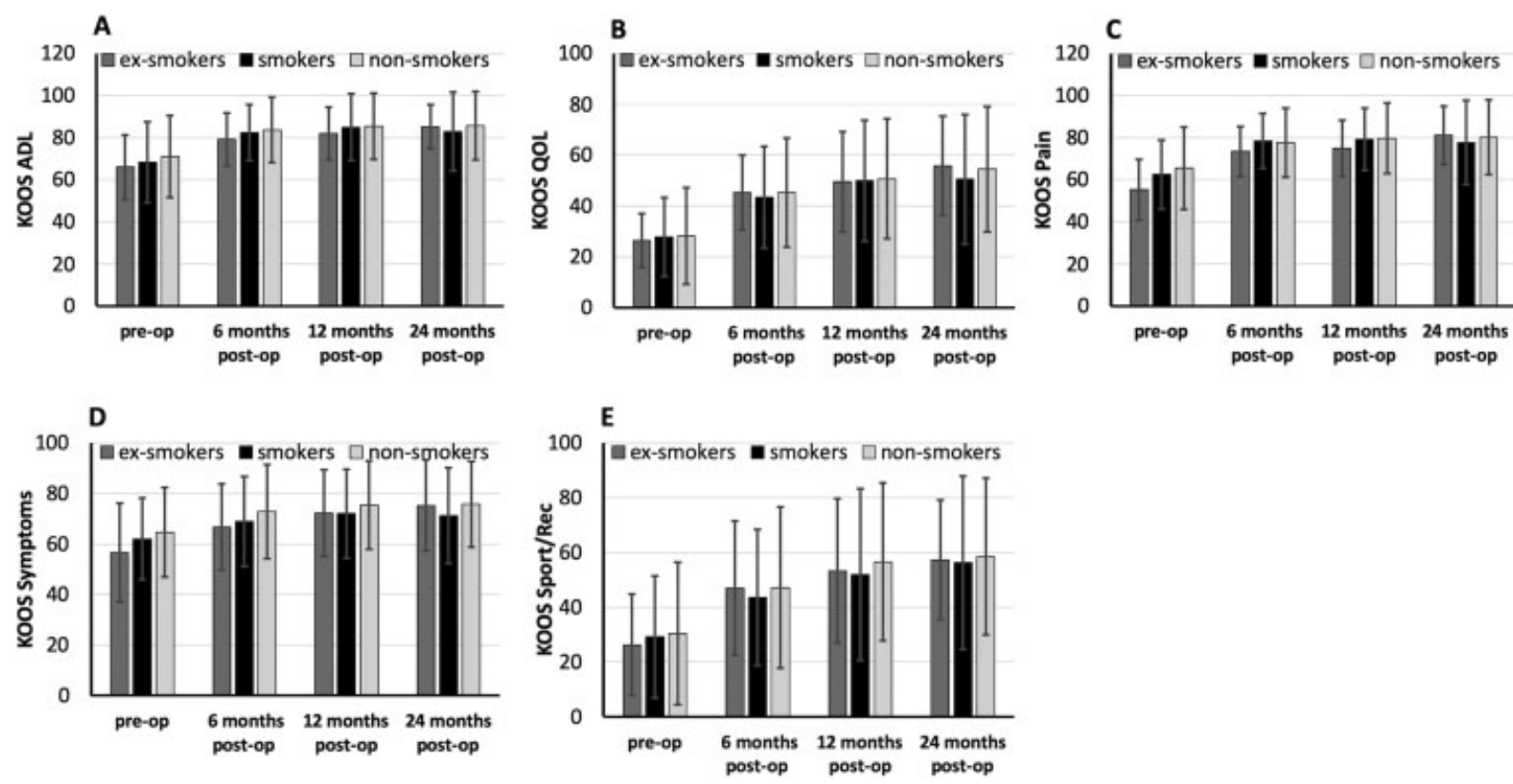

Fig. 2 Outcomes of ex-smokers, non-smokers and smokers analyzed by the five KOOS subscores. (A) The Knee Injury and Osteoarthritis Outcome Score (KOOS) ADL (function in daily living), (B) KOOS QOL (knee-related quality of live), (C) KOOS pain, (D) KOOS symptoms, (E) KOOS sport/recreation. There were no significant differences detected between the three groups at 6,12 , and 24 months follow-ups. ADL, activity of daily living; Post-op, postoperative; Pre-op, preoperative; QOL, quality of life. 


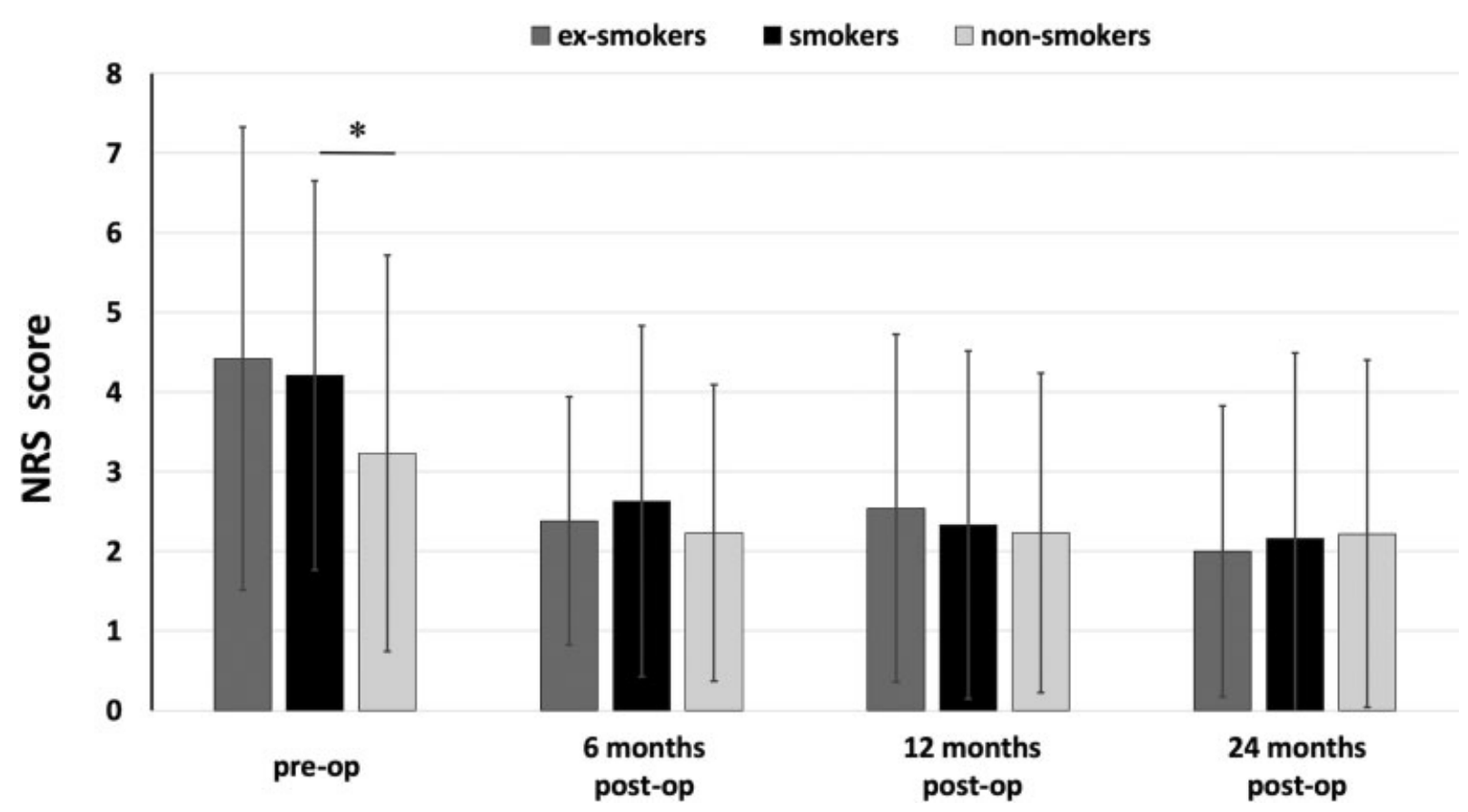

Fig. 3 Clinical outcomes of ex-smokers, nonsmokers and smokers analyzed by means of the numeric rating scale (NRS). Only the preoperative NRS of nonsmokers as compared with smokers was significantly lower $(p=0.013)$. No significant differences between the three groups were detected at 6, 12, and 24 months follow-ups. Post-op, postoperative; Pre-op, preoperative.

have entered datasets of their patients in this international (Germany, Austria, and Switzerland) and longitudinal multicenter registry preoperatively, as well as at 6,12 , and 24 months of follow-ups. Patients who are at least 18 years old, have a personal e-mail address, have given written informed consent, and had surgical treatment of cartilage defects in the knee, hip, or ankle are eligible to take part in the German Cartilage Registry. The study was approved by the local ethical committee (approval number: 105/13) and registered at the DRKS web site (DRKS00005617). Data were collected applying a web-based remote data entry system. Patient- and defect-specific parameters were evaluated. The patient cohort investigated in the present study was divided into three groups: ex-smokers, nonsmokers, and smokers.

\section{Evaluated Parameters}

Recorded parameters were age, sex, body mass index (BMI), weight, height, defect size, the need for additional reconstruction of the subchondral bone defect, number of previous knee surgeries, and defect location.

Clinical outcomes were analyzed by means of the Knee Injury and Osteoarthritis Outcome Score (KOOS) and a numeric rating scale (NRS) for pain description. The KOOS is a well-established patient-reported questionnaire comprising the five subscales KOOS pain, KOOS symptoms, KOOS ADL (activity of daily living), KOOS sports/recreation, and KOOS QOL (knee-related quality of live).

Also, patient satisfaction was evaluated. Original data were given as categorical variables. To perform additional statistical analysis of nominally scaled parameters, a patient satisfaction score was applied as follows: "excellent" $=1$, "good" $=2$, "fair" $=3$, and "poor" $=4$.

\section{Statistical Analysis}

Descriptive cohort data are presented as means \pm standard deviations or percentages. SPSS (version 21, IBM Corp.) was employed to conduct statistical analysis. Analysis of variance (ANOVA) was applied to analyze nominally scaled parameters of KOOS, KOOS subscores, NRS, and patient satisfaction score. Relationships between categorical variables of patient satisfaction were tested using a Chi-square test. An error probability $<5 \%(p<0.05)$ was considered statistically significant.

\section{Results}

Of the 281 patients, 225 (80.1\%) were nonsmokers, 43 (15.3\%) were smokers, and 13 (4.6\%) were ex-smokers. Age, sex, BMI, height, defect size, the need for additional reconstruction of the subchondral bone defect, number of previous knee surgeries, and defect location were not significantly different between groups. Interestingly, nonsmokers had a significantly lower weight as compared with smokers $(p=0.032$; - Table 1$)$.

In the group of ex-smokers, $92.3 \%$ of patients responded to the KOOS questionnaire at 6,12 , and 24 months of followups, respectively. In the group of smokers, there were $93 \%$ KOOS responders at all three follow-up time points, and $96.4 \%$ of nonsmokers entered their KOOS scores in the webbased data collection system at 6,12 , and 24 months.

No significant differences between the three groups with respect to KOOS, KOOS subscores, and NRS at 6, 12, and 24 months of follow-ups were detected (-Figs. 1-3). Only the preoperative NRS of nonsmokers as compared with smokers was significantly lower $(p=0.013)$. The groups showed the following increase of the KOOS over time: 


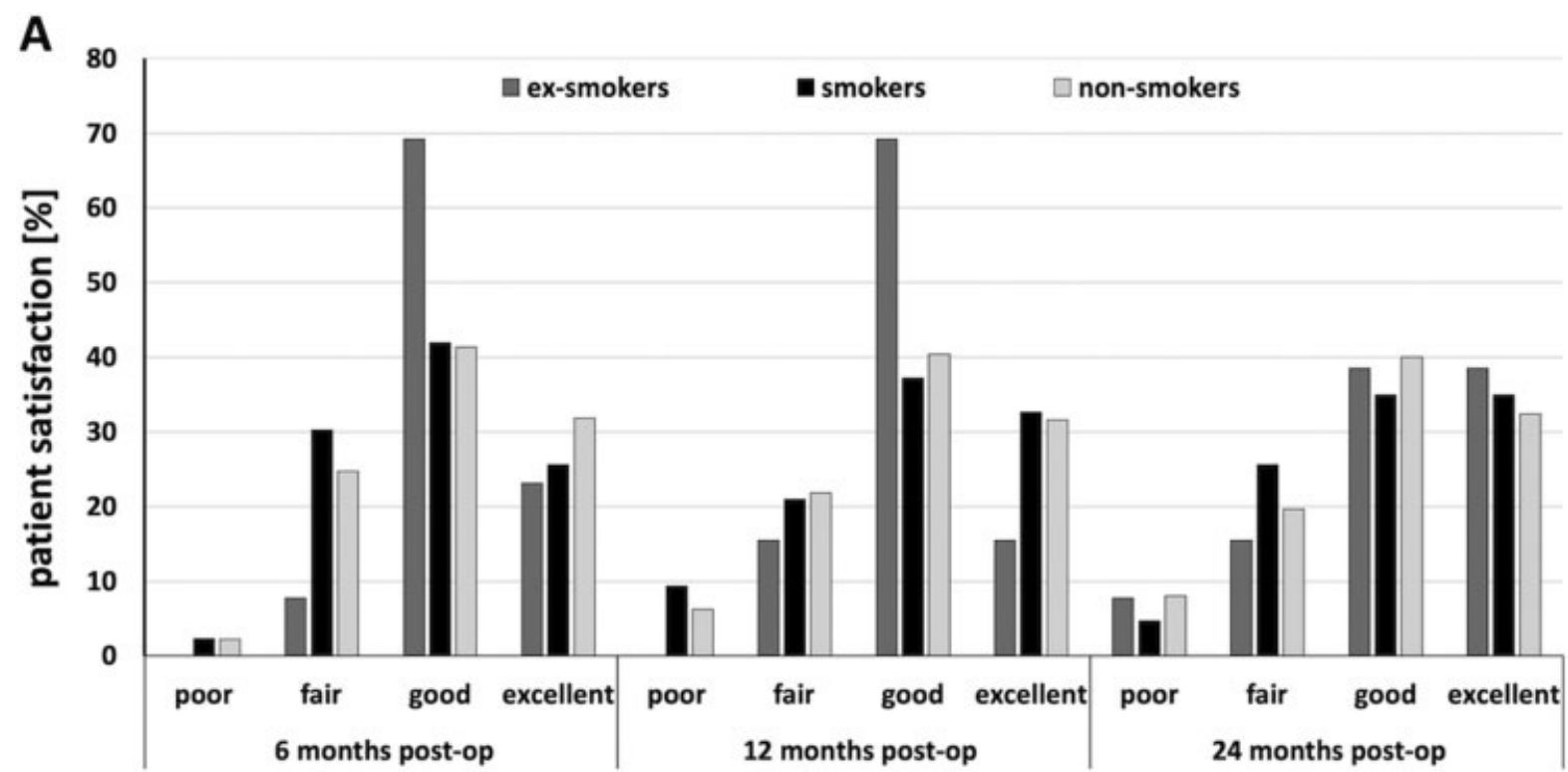

B

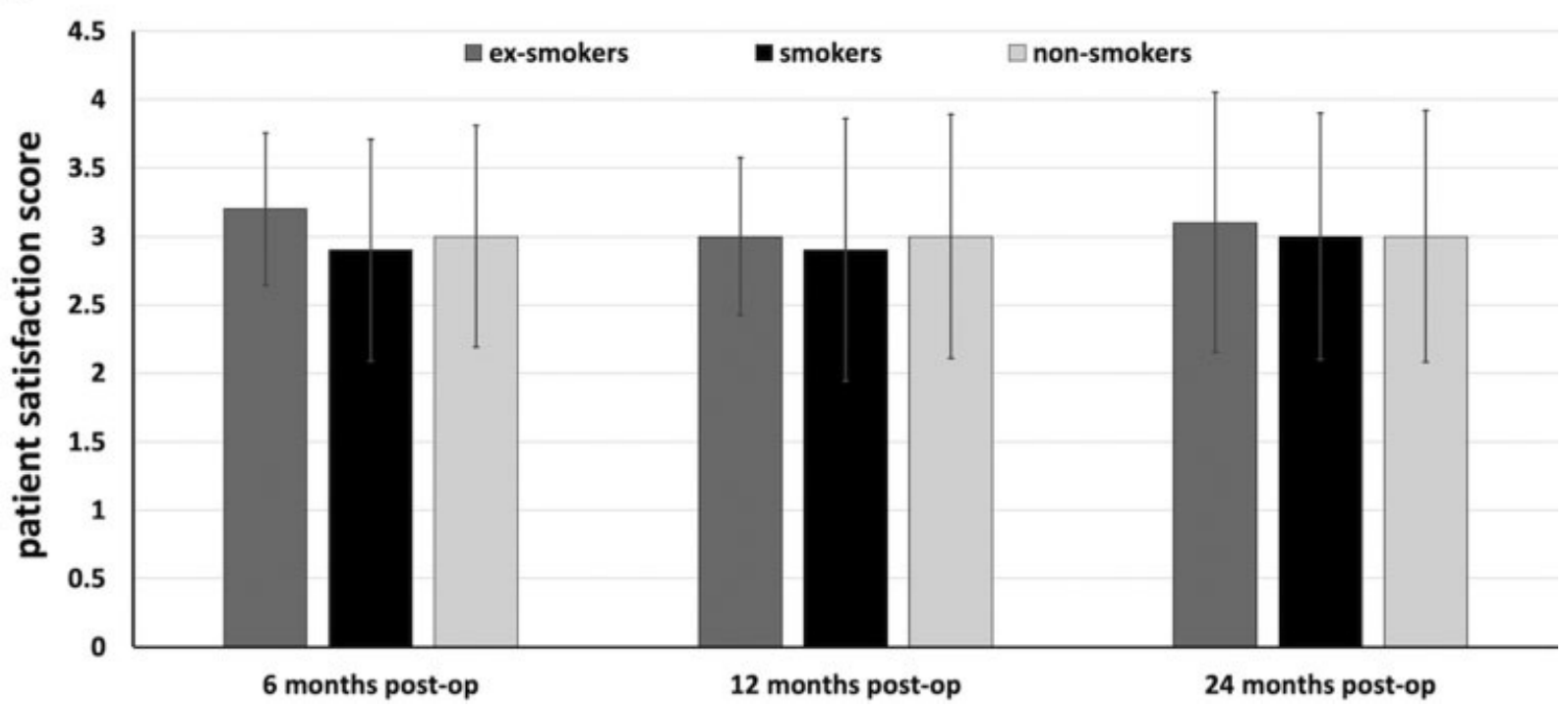

Fig. 4 Patient̀s satisfaction with the outcome was evaluated. Patients were able to choose from "excellent," "good," "fair" or "poor," as shown in (A). To perform additional statistical analysis of patient satisfaction a score was applied as follows: "excellent" $=1$, "good" $=2$, "fair" $=3$, and "poor" $=4$ (B). There were no significant differences detected between the three groups at 6, 12, and 24 months follow-ups.

ex-smokers: preoperative $=53.8 \pm 12.4,6$ months $=68.8$ \pm 13.1 , 12 months $=72.3 \pm 14.2$, and 24 months $=76.6$ \pm 13.1 ; smokers: preoperative $=57.9 \pm 16.3,6$ months $=71.0 \pm 13.8,12$ months $=74.4 \pm 16.7$, and 24 months $=73.6 \pm 19.4 ;$ nonsmokers: preoperative $=59.9 \pm 17.2,6$ months $=72.5 \pm 16.2, \quad 12$ months $=75.8 \pm 16.6$, and 24 months $=76.6 \pm 17.2$.

Pain analyzed using the NRS decreased from preoperative to 24 months: ex-smokers: preoperative $=4.4 \pm 2.9,6$ months $=2.4 \pm 1.6,12$ months $=2.5 \pm 2.2$, and 24 months $=2.0 \pm 1.8$; smokers: preoperative $=4.2 \pm 2.5,6$ months $=2.6 \pm 2.2,12$ months $=2.3 \pm 2.2$, and 24 months $=2.2$ \pm 2.3 ; nonsmokers: preoperative $=3.2 \pm 2.5,6$ months $=2.2$ $\pm 1.9,12$ months $=2.2 \pm 2.0$, and 24 months $=2.2 \pm 2.2$.
Patient satisfaction was also not significantly different between groups ( - Fig. 4A, B). None of the ex-smokers voted "poor" at 6 and 12 months. Instead, 69.2\% of ex-smokers voted "good" at 6 and 12 months. Smokers and nonsmokers gave very similar answers regarding their satisfaction at 6 , 12, and 24 months. At 24 months, all three groups voted very similar. Patient satisfaction score was not significantly different between groups and ranged between 2.9 and 3.2. At 6 months, the score was $3.2 \pm 1.0$ for ex-smokers, $2.9 \pm 0.8$ for smokers, and $3 \pm 0.8$ for nonsmokers; at 12 months, $3.0 \pm 1.0$ for ex-smokers, $2.9 \pm 1.0$ for smokers, and $3.0 \pm 0.9$ for nonsmokers; and at 24 months, $3.1 \pm 1.0$ for ex-smokers, $3.0 \pm 0.9$ for smokers, and $3.0 \pm 0.9$ for nonsmokers. 


\section{Discussion}

In the present study, we did not find evidence that the smoking behavior affects the outcome of third-generation $\mathrm{ACI}$ in the knee until 24 months following surgery. This finding is compatible with results from an earlier investigation demonstrating that there is no influence of smoking on the risk of reintervention after $\mathrm{ACI} .^{21}$ However, our conclusion stands in contrast to a study that was published a decade ago reporting poorer results in smokers than in nonsmokers after $\mathrm{ACI}$ in the knee. ${ }^{22}$ In this single-center, case-controlled study, smokers showed a significantly lower Modified Cincinnati Knee Score pre- and postoperatively as compared with nonsmokers, and smokers demonstrated significantly less improvement after 2 years than nonsmokers. While our study included a larger number of patients with data collected from multiple study centers, we decided to employ the Knee Injury and Osteoarthritis Outcome Score (KOOS) instead of the Modified Cincinnati Knee Score. The KOOS subscores were recommended by the International Cartilage Repair Society (ICRS) as basic assessment tools to investigate articular cartilage repair since they show good psychometric properties and provide relevant and quantitative data including pain and joint function. ${ }^{23}$ The KOOS has been validated as reliable and responsive for patients suffering from focal cartilage lesions. ${ }^{24-26}$

The outcome of our study is supported by findings of several previous investigations. A recent meta-analysis suggests that there is an inverse association between smoking and osteoarthritis in the knee, meaning that smoking protects from this cartilage degeneration. ${ }^{27}$ A clinical study in healthy patients showed that smoking is associated with increased tibial cartilage volume. ${ }^{28}$ Moreover, in vitro studies demonstrated that nicotine has a positive effect on chondrocyte metabolism. ${ }^{29,30}$ Hence, we believe it is likely that smoking does not negatively affect cartilage repair procedures. On the other side, it has been concluded that smoking impairs healing of several musculoskeletal tissues. $^{12}$ In particular, there is evidence that smoking is associated with delayed bone healing. ${ }^{13-17}$ Also, it was reported that smokers have a higher risk for impaired regeneration of wounds of the skin and other soft tissues. $^{31,32}$

The negative effects of smoking on healing of bone and soft tissue are caused by multiple mechanisms, including vasoconstriction, decreased oxygen delivery, and reduced fibroblast migration. ${ }^{33-36}$ Cartilage, however, is an avascular tissue and the decrease of microperfusion and oxygenation by nicotine and carbon monoxide may not affect cartilage healing as much as bone and soft-tissue healing. Instead, an in vitro experiment demonstrated stimulating effects of nicotine on human chondrocytes derived from healthy patients and osteoarthritis patients leading to enhanced cell proliferation and collagen synthesis. ${ }^{30}$ Despite these considerations, in our present study, the group of smokers did not achieve a better outcome after third-generation ACI than nonsmokers or ex-smokers.
The preoperative NRS of smokers was significantly higher than in the group of nonsmokers. This finding is in agreement with other previous studies reporting that smokers experience more musculoskeletal pain than nonsmokers. ${ }^{37-39}$ It is thought that elevated levels of proinflammatory mediators can amplify pain in smokers. ${ }^{40,41}$

\section{Strengths and Limitations}

Strengths of this study include the way data were collected. We used registry data from a large number of "real world patients" with similar patient- and defect-specific parameters. The reported data may be closer to reality as in contrast to highly selected cartilage defect patients enrolled in randomized clinical trials that are suggested not to be representative of patients in an orthopaedic practice. ${ }^{24,42}$ Data from the German Cartilage Registry were collected by multiple international study centers using a web-based remote data entry system. ${ }^{20}$

Limitations are that register studies are subject to selection bias, since it cannot be guaranteed that every single patient receiving $\mathrm{ACI}$ will be documented. Also, there might have been unconsidered confounding variables influencing the outcome. Yet, it has been postulated that randomized controlled trials should be supplemented by observational studies with data from multicenter patient registries. ${ }^{43-45}$

\section{Conclusion}

Our data suggest that smoking does not affect the outcome within the first 2 years after third-generation ACI. Despite this finding, we recommend that prior to cartilage repair procedures surgeons inform their patients about the various deleterious effects of smoking on health.

\section{Funding \\ None.}

Conflict of Interest

None declared.

\section{References}

1 Guermazi A, Hayashi D, Roemer FW, et al. Brief report: partial- and full-thickness focal cartilage defects contribute equally to development of new cartilage damage in knee osteoarthritis: the multicenter osteoarthritis study. Arthritis Rheumatol 2017;69(03):560-564

2 Kim JK, Vaidya R, Lee SK, et al. Clinical and radiological changes after microfracture of knee chondral lesions in middle-aged Asian patients. Clin Orthop Surg 2019;11(03):282-290

3 Wang D, Chang B, Coxe FR, et al. Clinically meaningful improvement after treatment of cartilage defects of the knee with osteochondral grafts. Am J Sports Med 2019;47(01):71-81

4 Zouzias IC, Bugbee WD. Osteochondral allograft transplantation in the knee. Sports Med Arthrosc Rev 2016;24(02):79-84

5 Everhart JS, Jiang EX, Poland SG, Du A, Flanigan DC. Failures, reoperations, and improvement in knee symptoms following matrix-assisted autologous chondrocyte transplantation: a meta-analysis of prospective comparative trials. Cartilage 2019. Doi: $10.1177 / 1947603519870861$ 
6 Krill M, Early N, Everhart JS, Flanigan DC. Autologous chondrocyte implantation (ACI) for knee cartilage defects: a review of indications, technique, and outcomes. JBJS Rev 2018;6(02):e5

7 Niemeyer P, Albrecht D, Andereya S, et al. Autologous chondrocyte implantation (ACI) for cartilage defects of the knee: a guideline by the working group "Clinical Tissue Regeneration" of the German Society of Orthopaedics and Trauma (DGOU). Knee 2016;23(03): 426-435

8 Fu M, Castellano Y, Tigova O, et al; EUREST-PLUS consortium. Prevalence and correlates of different smoking bans in homes and cars among smokers in six countries of the EUREST-PLUS ITC Europe Surveys. Tob Induc Dis 2019;16:A8

9 Kastaun S, Kotz D, Brown J, Shahab L, Boeckmann M. Public attitudes towards healthcare policies promoting tobacco cessation in Germany: results from the representative German study on tobacco use (DEBRA study). BMJ Open 2019;9(08):e026245

10 Kotz D, Böckmann M, Kastaun S. The use of tobacco, e-cigarettes, and methods to quit smoking in Germany. Dtsch Arztebl Int 2018; 115(14):235-242

11 Peacock A, Leung J, Larney S, et al. Global statistics on alcohol, tobacco and illicit drug use: 2017 status report. Addiction 2018; 113(10):1905-1926

12 Lee JJ, Patel R, Biermann JS, Dougherty PJ. The musculoskeletal effects of cigarette smoking. J Bone Joint Surg Am 2013;95(09): 850-859

13 McKee MD, DiPasquale DJ, Wild LM, Stephen DJ, Kreder HJ, Schemitsch EH. The effect of smoking on clinical outcome and complication rates following Ilizarov reconstruction. J Orthop Trauma 2003;17(10):663-667

14 Adams CI, Keating JF, Court-Brown CM. Cigarette smoking and open tibial fractures. Injury 2001;32(01):61-65

15 Castillo RC, Bosse MJ, MacKenzie EJ, Patterson BMLEAP Study Group. Impact of smoking on fracture healing and risk of complications in limb-threatening open tibia fractures. J Orthop Trauma 2005;19(03):151-157

16 Harvey EJ, Agel J, Selznick HS, Chapman JR, Henley MB. Deleterious effect of smoking on healing of open tibia-shaft fractures. Am J Orthop 2002;31(09):518-521

17 Schmitz MA, Finnegan M, Natarajan R, Champine J. Effect of smoking on tibial shaft fracture healing. Clin Orthop Relat Res 1999;(365):184-200

18 Blackwell R, Schmitt LC, Flanigan DC, Magnussen RA. Smoking increases the risk of early meniscus repair failure. Knee Surg Sports Traumatol Arthrosc 2016;24(05):1540-1543

19 Santiago-Torres J, Flanigan DC, Butler RB, Bishop JY. The effect of smoking on rotator cuff and glenoid labrum surgery: a systematic review. Am J Sports Med 2015;43(03):745-751

20 Maurer J, Grotejohann B, Jenkner C, et al. A registry for evaluation of efficiency and safety of surgical treatment of cartilage defects: the German Cartilage Registry (KnorpelRegister DGOU). JMIR Res Protoc 2016;5(02):e122

21 Jungmann PM, Salzmann GM, Schmal H, Pestka JM, Südkamp NP, Niemeyer P. Autologous chondrocyte implantation for treatment of cartilage defects of the knee: what predicts the need for reintervention? Am J Sports Med 2012;40(01):58-67

22 Jaiswal PK, Macmull S, Bentley G, Carrington RW, Skinner JA, Briggs TW. Does smoking influence outcome after autologous chondrocyte implantation?: a case-controlled study J Bone Joint Surg Br 2009;91(12):1575-1578

23 Mithoefer K, Saris DB, Farr J, et al. Guidelines for the design and conduct of clinical studies in knee articular cartilage repair: international cartilage repair society recommendations based on current scientific evidence and standards of clinical care. Cartilage 2011;2(02):100-121

24 Hochrein A, Zinser W, Spahn G, et al. What parameters affect knee function in patients with untreated cartilage defects: baseline data from the German Cartilage Registry. Int Orthop 2019;43(05): 1107-1112

25 Bekkers JE, de Windt TS, Raijmakers NJ, Dhert WJ, Saris DB. Validation of the Knee Injury and Osteoarthritis Outcome Score (KOOS) for the treatment of focal cartilage lesions. Osteoarthritis Cartilage 2009;17(11):1434-1439

26 Roos EM, Roos HP, Ekdahl C, Lohmander LS. Knee injury and Osteoarthritis Outcome Score (KOOS)-validation of a Swedish version. Scand J Med Sci Sports 1998;8(06):439-448

27 Kong L, Wang L, Meng F, Cao J, Shen Y. Association between smoking and risk of knee osteoarthritis: a systematic review and meta-analysis. Osteoarthritis Cartilage 2017;25(06):809-816

28 Racunica TL, Szramka M, Wluka AE, et al. A positive association of smoking and articular knee joint cartilage in healthy people. Osteoarthritis Cartilage 2007;15(05):587-590

29 Gullahorn L, Lippiello L, Karpman R. Smoking and osteoarthritis: differential effect of nicotine on human chondrocyte glycosaminoglycan and collagen synthesis. Osteoarthritis Cartilage 2005;13 (10):942-943

30 Ying X, Cheng S, Shen Y, et al. Nicotine promotes proliferation and collagen synthesis of chondrocytes isolated from normal human and osteoarthritis patients. Mol Cell Biochem 2012;359 $(1,2): 263-269$

31 Sørensen LT. Wound healing and infection in surgery. The clinical impact of smoking and smoking cessation: a systematic review and meta-analysis. Arch Surg 2012;147(04):373-383

32 Theocharidis V, Katsaros I, Sgouromallis E, et al. Current evidence on the role of smoking in plastic surgery elective procedures: a systematic review and meta-analysis. J Plast Reconstr Aesthet Surg 2018;71(05):624-636

33 Silverstein P. Smoking and wound healing. Am J Med 1992;93 (1A):22S-24S

34 Hwang K, Son JS, Ryu WK. Smoking and flap survival. Plast Surg (Oakv) 2018;26(04):280-285

35 Wong LS, Martins-Green M. Firsthand cigarette smoke alters fibroblast migration and survival: implications for impaired healing. Wound Repair Regen 2004;12(04):471-484

36 Wong LS, Green HM, Feugate JE, Yadav M, Nothnagel EA, MartinsGreen M. Effects of "second-hand" smoke on structure and function of fibroblasts, cells that are critical for tissue repair and remodeling. BMC Cell Biol 2004;5:13

37 Karim A, Pandit H, Murray J, Wandless F, Thomas NP. Smoking and reconstruction of the anterior cruciate ligament. J Bone Joint Surg Br 2006;88(08):1027-1031

38 Mallon WJ, Misamore G, Snead DS, Denton P. The impact of preoperative smoking habits on the results of rotator cuff repair. J Shoulder Elbow Surg 2004;13(02):129-132

39 Amin S, Niu J, Guermazi A, et al. Cigarette smoking and the risk for cartilage loss and knee pain in men with knee osteoarthritis. Ann Rheum Dis 2007;66(01):18-22

40 Yanbaeva DG, Dentener MA, Creutzberg EC, Wesseling G, Wouters EF. Systemic effects of smoking. Chest 2007;131(05):1557-1566

41 O'Loughlin J, Lambert M, Karp I, et al. Association between cigarette smoking and C-reactive protein in a representative, population-based sample of adolescents. Nicotine Tob Res 2008;10(03):525-532

42 Engen CN, Engebretsen L, Årøen A. Knee cartilage defect patients enrolled in randomized controlled trials are not representative of patients in orthopedic practice. Cartilage 2010;1(04):312-319

43 Black N. Why we need observational studies to evaluate the effectiveness of health care. BMJ 1996;312(7040):1215-1218

44 Hannan EL. Randomized clinical trials and observational studies: guidelines for assessing respective strengths and limitations. JACC Cardiovasc Interv 2008;1(03):211-217

45 Silverman SL. From randomized controlled trials to observational studies. Am J Med 2009;122(02):114-120 